\title{
АНАЛИЗ КАЧЕСТВА ЗКИЗНИ МИРНОГО НАСЕЛЕНИЯ, ПРОЖИВАЮЩЕГО В УСЛОВИЯХ ВООРУЖЕННОГО КОНФЛИКТА
}

\begin{abstract}
АннотАция. В статье представлены результаты анализа качества жизни мирного населения, проживающего в условиях вооруженного конфликта. Эмпирическое исследование проходило на Донбассе. В исследовании приняло участие 723 человека в возрасте от 17 до 75 лет. Выборка была разбита на две группы: первая — жители районов малоинтенсивных обстрелов (РМО), вторая - население из районов интенсивных обстрелов (РИО). Выявлено, что нормальное качество жизни наблюдается у большинства респондентов первой группы по параметрам: жилищные условия, район проживания, семья, сексуальная жизнь, отдых, социальная поддержка, здоровье близких, но наблюдается сниженное качество жизни по показателям: материальный достаток, питание, положение в обществе, работа, духовные потребности, личное здоровье, душевный покой, жизнь в целом. Обнаружено, что оценки качества жизни во второй группе значительно ниже, чем в первой, практически по всем параметрам. Установлено, что основными показателями, которые находятся в зоне нормальной жизни для людей из второй группы, являются семья и социальная поддержка. Определено, что у респондентов-мужчин первой группы уровень мотивации на достижение успеха выше, чем у женщин этой группы; во второй группе количество мужчин с низким уровнем мотивации преобладает. Сделан вывод о том, что в целом у респондентов двух исследуемых групп наиболее выраженной является оценка «средняя удовлетворенностью жизнью».

кЛючЕВЫЕ СЛОВА. Вооруженный конфликт; мирные жители; качество жизни; мотивация; удовлетворенность жизнью.

ИНФОРМАЦИЯ О СТАТЬЕ. Дата поступления 15 ноября 2017 г.; дата принятия к печати 19 марта 2018 г.; дата онлайн-размещения 09 апреля 2018 г.

ФИНАНСИРОВАНИЕ. Исследование выполнено в рамках Инициативного научного проекта фундаментального характера в рамках реализации внутреннего гранта ЮФУ (ВнГр - 07/2017-01).
\end{abstract}

Ye. N. Ryadinskaya

Southern Federal University,

Rostov-on-Don, Russian Federation

\section{ANALYSIS OF LIFE QUALITY OF CIVILIANS LIVING IN ARMED CONFLICT ENVIRONMENT}

\begin{abstract}
The article presents results of the analysis of the life quality of civilians living in the armed conflict environment. An empirical study took place in Donbass. The study involved 723 people aged from 17 to 75 . The selection was divided into two groups: the first group was the residents of the low-intensity shooting areas (ALIS), the second group was the population from the areas of intensive shooting (AIS). The author reveals that the majority of the respondents in the first group have normal life quality in terms of the parameters: living conditions, area of residence, family, sex life, recreation, social support, health of relatives, but there is a diminished quality of life in terms of indicators: material prosperity, nutrition, social position, work, spiritual needs, personal health, peace of mind, life in general. It was found that the life quality evaluation in the second group is significantly lower than in the first group, almost in all the parameters. The article specifies that the main indicators that exist in the zone of normal life for people from the second group are family and social support. The author indicates that the level of motivation to achieve success among the male respondents
\end{abstract}

\section{Baikal Research Journal}

электронный научный журнал Байкальского государственного университета 
of the first group is higher than that of women in this group; in the second group the number of men with a low level of motivation prevails. It was concluded that the respondents of the two groups studied had the most pronounced «average satisfaction with life» assessment in general.

KEYWORDS. Armed conflict; civilians; quality of life; motivation; satisfaction with life. ARTICLE INFO. Received November 15, 2017; accepted March 19, 2018; available online April 09, 2018.

ACKNOWLEDGEMENTS. The research was carried out within the framework of the Initiative Scientific Project of a fundamental nature according to the goals of the internal Southern Federal University grant ( $\mathrm{BH} \Gamma \mathrm{p}-07$ / 2017-01).

Современное состояние общества характеризуется тенденциями к возникновению разного рода конфликтов и террористических угроз в тех странах, где имеет место разрыв между интересами личности и социума. Подобные тенденции влекут за собой рост политической и социально-экономической напряженности, проявлений экстремизма, усиливая психологическую нестабильность. В такие периоды, когда в обществе надолго ухудшаются условия проживания, уровень жизни людей заметно падает.

Качество жизни, являясь важной социальной категорией, определяется структурой потребностей человека и возможностями их реализации. Некоторые авторы [1; 2] подчеркивают, что оценка качества жизни включает как объективные, так и субъективные показатели. $\mathrm{K}$ первым можно отнести следующие: удовлетворенность бытовыми условиями жизни, характером выполняемой работы, финансовым положением, возможностью повышения образовательного уровня, профессионального роста, сексуальными отношениями, социальной поддержкой, а также удовлетворенность состоянием здоровья, душевным состоянием и жизнью в целом. Субъективные показатели качества жизни человека определяются степенью удовлетворённости указанными сторонами жизнедеятельности [3].

Известно, что человек, как правило, страдает от низкого качества жизни и испытывает удовлетворение от высокого ее качества, независимо от сферы его деятельности и характеристик личной жизни [4]. Индивид осознанно старается улучшить качество собственной жизни - получает образование, трудится, стремится к продвижению по карьерной лестнице, прилагает усилия к тому, чтобы добиться признания в обществе. Как показывает практика, в экстремальных ситуациях под воздействием разного рода стресс-факторов качество жизни человека снижается, удовлетворение его потребностей затруднено, что может приводить к фрустрационным состояниям [5, р. 89.].

C 2014 года и до настоящего времени на Востоке Украины происходит вооруженный конфликт, в зоне которого проживает большое количество мирных жителей. Кроме постоянного воздействия негативных стресс-факторов, связанных с угрозой жизни и здоровью (многочасовые обстрелы; действия диверсионных групп; осуществление терактов; гибель членов семьи, близких; вероятность собственной гибели, переживание за жизнь и здоровье детей; собственное ранение; ранение близких или родственников; вероятность стать заложником; наличие без вести пропавших родственников в период вооруженного конфликта и др.), на население воздействует множество иных стресс-факторов социального, экономического и политического характера. Перечислим основные из них:

- невозможность осуществления нормальной жизнедеятельности, в том числе трудовой, сложности с трудоустройством;

- финансовая нестабильность (невозможность выплат по кредитам, оплаты коммунальных платежей, медицинских и образовательных услуг);

\section{Baikal Research Journal}

электронный научный журнал Байкальского государственного университета 
- социально-бытовая неустроенность (отсутствие разнообразия в покупках, продуктовая блокада; перебои в обеспечении водой, электро- и газоснабжении; неустойчивость работы стационарной и мобильной связи, интернета; отсутствие организованного отдыха детей и взрослых);

- трудности реализации механизмов государственной социальной защиты, отсутствие необходимых социальных выплат (пенсий, пособий);

- проблемы обеспечения населения услугами отраслей социальной инфраструктуры (ограничения в деятельности общеобразовательных, средних профессиональных и высших учебных заведений; невозможность в полном объеме получить качественное медицинское обслуживание);

- физические разрушения собственных домов, жилых массивов, объектов инфраструктуры и производств;

- несоблюдение гражданских прав населения и осознание данного факта (собственное внутреннее несогласие со сложившейся системой общественных отношений; невозможность свободно высказывать свое мнение; затрудненность территориального передвижения через блок-посты) [6;2].

Под воздействием данных стресс-факторов у людей, проживающих непосредственно в зоне конфликта, может существенно снижаться качество и удовлетворенность жизнью, а острота возникших проблем делает их изучение весьма актуальным.

Целью исследования является анализ качества жизни мирного населения, проживающего в зоне вооруженного конфликта.

Эмпирическое исследование проводилось в течение трех лет (с 2014 по 2017 гг.). В качестве респондентов в нем приняли участие 723 человека в возрасте от 17 до 75 лет, среди которых 302 мужчины и 421 женщина, из восьми городов Донбасса (Горловка, Дебальцево, Докучаевск, Донецк, Енакиево, Иловайск, Макеевка, Ясиноватая), находящихся на территориях с разной интенсивностью боевых действий. С целью проведения сравнительного анализа нами были сформированы две группы респондентов. Первая группа состояла из жителей районов малоинтенсивных обстрелов (РМО) в количестве 335 человек $(40,0 \%$ мужчин и $60,0 \%$ женщин), во вторую вошло 388 человек (43,3\% мужчин и 56,7 \% женщин), проживающих в районах интенсивных обстрелов (РИО).

Следует подчеркнуть, что при проведении эмпирических исследований качества жизни авторы, как правило, встречаются с различными проблемами методологического характера, которые, в частности, связаны с тем, что респонденты имеют представление лишь о некоторых аспектах удовлетворенности собственной жизнью. Так, анализируя качество жизни на основании данных, полученных в результате использования психологических методик, мы на самом деле исследуем самосознание человека, систему значимых для него социальных связей, его собственное отношение к происходящим событиям, что в большей степени отражает некое качество состояния личности в реальных условиях, а не качество его жизни в целом. Таким образом, удовлетворенность жизнью можно рассматривать через основные стереотипы о "хорошей жизни», которые сформировались в конкретном социуме. Общий уровень удовлетворенности в зависимости от временного континуума может свидетельствовать о степени несоответствия между реальностью и личностными конструктами «хорошей жизни». Иными словами, удовлетворенность жизнью можно охарактеризовать степенью разрыва между ожиданиями человека и его реальным положением. На уровне обыденного сознания респонденты оценивают качество своей жизни посредством простых наблюдений и житейских представлений, которые сложились в их социальном окружении.

\section{Baikal Research Journal}

электронный научный журнал Байкальского государственного университета 
В связи с вышеизложенным, для анализа качества жизни мирных жителей, проживающих в условиях вооруженного конфликта, нами использовались как индивидуальные беседы, так и комплекс психологических методик: опросник оценки качества жизни З. Ф. Дудченко, методика-шкала Э. Динера «Удовлетворенность жизнью» (SWLS), опросник T. Элерса (мотивация на достижение успеха и избегание неудач), шкала оценки потребности в достижении Ю. М. Орлова. Результаты полученных эмпирических данных были подвергнуты математической обработке с использованием t-критерия Стьюдента и $\varphi^{*}-$ критерия Фишера.

Исследуя самооценку качества жизни по опроснику 3. Ф. Дудченко, мы оценивали следующие параметры: материальный достаток (общее благосостояние семьи; личный заработок), жилищные условия (размеры жилой площади; благоустроенность квартиры); район проживания (климатические, экологические, бытовые условия); семья; питание (разнообразие потребляемых продуктов, количество пищи); сексуальная жизнь; отдых (сон, физическая активность); положение в обществе; работа (отношения с руководителем, отношения с коллегами, профессиональный рост, удовлетворенность своей работой); духовные потребности; социальная поддержка; здоровье родственников (детей, мужа/жены); состояние своего здоровья; душевное состояние в последнее время (настроение, характер, переживания, удовлетворенность собой); жизнь в целом (работа, семья, бытовые условия, возможность отдохнуть). Результаты, полученные с применением данного опросника, представлены на рис. 1.

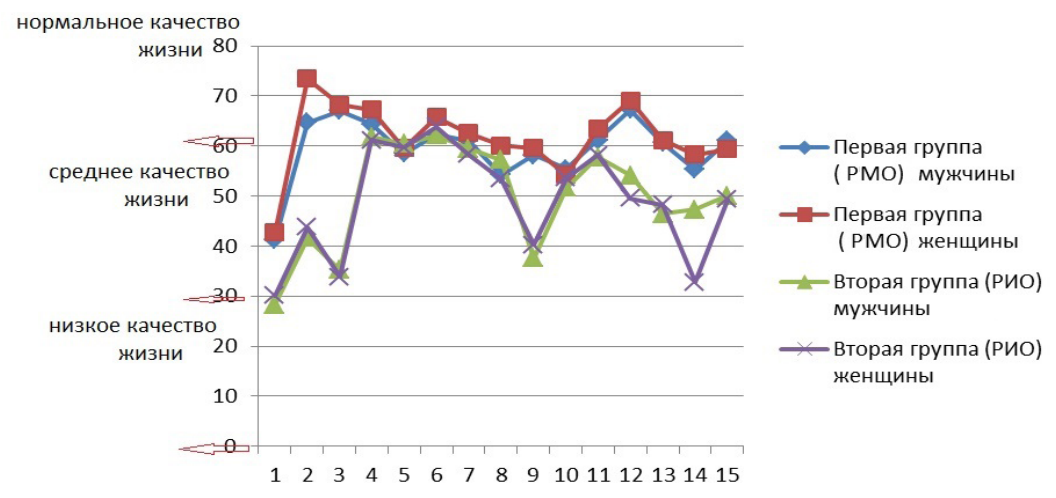

Примечание: 1 - материальный достаток. 2 - жилищные условия. 3 - район проживания. 4 - семья. 5 - питание. 6 - сексуальная жизнь. 7 - отдых. 8 - положение в обществе. 9 - работа. 10 - духовные потребности. 11 - социальная поддержка. 12 - здоровье близких. 13 - личное здоровье. 14 - душевный покой. 15 - жизнь в целом.

Рис. 1. Выраженность качества жизни у респондентов 2-х исследуемых групп в баллах (по методике З.Ф. Дудченко)

Как показано на рис. 1, нормальное качество жизни наблюдается у большинства мужчин и женщин первой группы (63,4 \% и $61,7 \%$ соответственно) по следующим параметрам: жилищные условия; район проживания; семья; сексуальная жизнь; отдых; социальная поддержка; здоровье близких. В то же время у более половины респондентов первой группы (60,4 \% мужчин, 55,7 \% женщин) выявлено сниженное качество жизни по таким показателям, как материальный достаток, питание, положение в обществе, работа, духовные потребности, личное здоровье, душевный покой. Жиизнь в целом оценивается респондентами первой группы в среднем диапазоне.

\section{Baikal Research Journal}


Анализируя оценки качества жизни респондентами второй группе (РИО), следует отметить, что полученные результаты значительно ниже, чем в первой группе практически по всем параметрам методики, о чем свидетельствуют статистически значимые различия по t-критерию Стьюдента (при $p<0,05)$.

Мужчины и женщины второй группы (57,7 \% и 53,6 \%) нормальной считают жизнь только по трем параметрам (семья, сексуальная жизнь, социальная поддержка), что возможно свидетельствует об их непростом положении, однако они уверены, что могут рассчитывать на поддержку семьи, родственников, друзей. Критерий «материальный достаток» находится у респондентов $(56,7 \%$ от общей выборки группы) в зоне низкого качества жизни. Свой доход они считают неадекватным относительно затраченных усилий, расценивают его как низкий. У женщин $(59$ \%) этой группы имеет низкое значение еще и критерий «душевное спокойствие», что является очевидным в силу их эмоциональности. Респонденты этой группы (79,7 \% мужчин и 65,9 \% женщин) в целом определяют свою жизнь как не соответствующую норме. Отсутствие элементарных гарантий жизни, постоянные обстрелы, в зоне которых проживают люди из второй исследуемой группы, неопределенное состояние политической ситуации, проблемы в осуществлении трудовой деятельности, ухудшение здоровья из-за постоянных стрессов, низкий уровень материального обеспечения и другие негативные факторы, на наш взгляд, создают существенные предпосылки для снижения качества жизни.

Таким образом, установлено, что качество жизни у людей, непосредственно проживающих в зоне интенсивных обстрелов (вторая группа), значительно ниже, чем у респондентов первой группы. Основными параметрами, которые находятся в зоне нормальной жизни для людей из второй группы, являются семья и социальная поддержка.

При анализе качества жизни людей, проживающих в условиях вооруженного конфликта, нам представляется интересным исследование их мотивационной направленности на достижение успеха и избегание неудач Мотивация - психофизиологический процесс, который управляет поведением человека, определяет его активность, направленность и устойчивость. Мотивацию также рассматривают как способность индивида деятельно удовлетворять свои потребности. Некоторые авторы указывают, что мотивация на успех относится к позитивной мотивации и стимулирует стремление человека к активной реализации его намерений [7]. Для исследования мотивационной направленности нами использовался опросник Т. Элерса (мотивация на достижение успеха и избегание неудач) (табл. 1).

Таблица 1

Выраженность мотивации на достижение успеха (Т. Элерс) в двух исследуемых группах (в \%)

\begin{tabular}{|c|l|r|r|r|r|}
\hline \multicolumn{2}{|c|}{ Параметры } & HMУ & \multicolumn{1}{c|}{ CMУ } & \multicolumn{1}{|c|}{ УВМУ } & \multicolumn{1}{|c|}{ BMУ } \\
\hline \multirow{2}{*}{ Первая группа (РМО) } & мужчины $(n=134)$ & 9,1 & 36,5 & 52,9 & 1,5 \\
\cline { 2 - 6 } & женщины $(n=201)$ & $33,3 *$ & $45,7 *$ & $21,0 *$ & - \\
\hline \multirow{2}{*}{ Вторая группа (РИО) } & мужчины $(n=168)$ & $24,5 *$ & 32,7 & 42,2 & 0,6 \\
\cline { 2 - 6 } & женщины $(n=220)$ & $38,6 *$ & $41,4 *$ & $19,1^{*}$ & 0,9 \\
\hline
\end{tabular}

Примечание: НМУ - низкая мотивация к успеху; СМУ — средний уровень мотивации; УВМУ умеренно высокий уровень мотивации; ВМУ - слишком высокий уровень мотивации к успеху. *статистически значимые различия при $p<0,05$ (по $\varphi^{*}-$ критерию Фишера).

Как видно из результатов, представленных в табл. 1, среди мужчин первой группы (PMO) у более чем половины (52,9 \%) выявлен умеренно высокий уровень мотивации, что характеризует их как людей, которые нацелены на успех, несмотря на экстремальные условия жизни.

\section{Baikal Research Journal}


У трети мужчин первой группы $(36,5$ \%) обнаружен средний уровень мотивации, который может свидетельствовать об их нацеленности на успех, но практические действия в этом случае зависят от различных внешних обстоятельств. Небольшое количество респондентов-мужчин имеют низкий $(9,1 \%)$ и слишком высокий $(1,5 \%)$ уровни мотивации. При высоком уровне мотивации на достижение успеха человеку свойственно реализовывать свои цели вопреки всему, не считаясь с окружением и обстоятельствами, при низком уровне мотивации наблюдается инертность и безучастность, отсутствие каких-либо определенных жизненных целей и ориентиров. Отметим, что, средний и умеренно высокий уровень мотивации говорят также о том, что респонденты адекватно оценивают значимость достижения успеха, его вероятность, а также субъективные эталоны достижения. Они активны, инициативны, ответственны, уверены в себе, настойчивы в осуществлении намеченного. В основе их деятельности, как правило, лежит надежда на успех и потребность в его достижении.

У женщин первой группы проявился в основном средний $(45,7 \%)$ и низкий $(33,3 \%)$ уровень мотивации, что связано, вероятнее всего, с большей социально-бытовой нагрузкой и накопившейся неуверенностью в ситуации неопределенности, нестабильности в обществе. У 21 \% женщин выявлен умеренно высокий уровень мотивации на успех. Следует подчеркнуть, что люди с выраженной ориентацией на успех оптимистичны во взглядах на жизнь, рассматривают необходимость решения задач как импульс к движению вперед, к развитию, реагируют на появление препятствий с оптимизмом и энергией. Они опираются на свои способности, реально оценивая и развивая их, прилагают усилия к достижению цели, считают, что успех во многом зависит только от них самих. Установлено, что мужчины первой группы более ориентированы на успех, чем женщины, о чем свидетельствуют, полученные в ходе исследования, статистически значимые различия при $\mathrm{p}<0,05$ (по $\varphi^{*}-$ критерию Фишера).

Во второй группе респондентов (РИО) мотивация на достижения успеха наиболее выражена у мужчин: умеренно высокий уровень у $42,2 \%$ респондентов и средний - у 32,7 \% , что говорит об их активности и стремлении достигать поставленных целей, проявляя умеренную инициативность и ответственность (рис. 2).

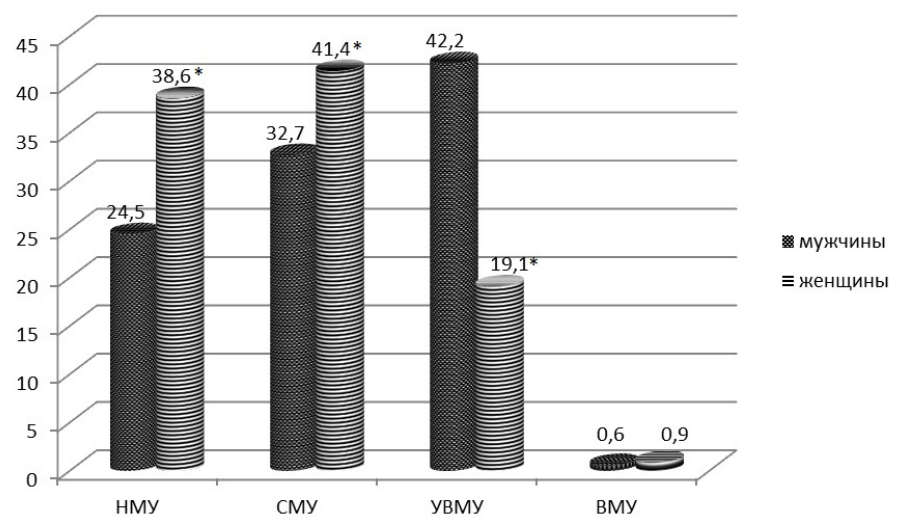

Примечание: НМУ - низкая мотивация к успеху; СМУ - средний уровень мотивации; УВМУ умеренно высокий уровень мотивации; ВМУ - слишком высокий уровень мотивации к успеху. *статистически значимые различия при $\mathrm{p}<0,05$ (по $\varphi^{*}-$ критерию Фишера).

Рис. 2. Выраженность мотивации на достижение успеха (Т. Элерс) во второй гpynnе (РИО) в \%

\section{Baikal Research Journal}


Отметим, что количество респондентов-мужчин второй группы $(24,5 \%)$, имеющих низкий уровень мотивации, значительно увеличилось в сравнении с первой группой $(9,1$ \%). Данный факт может свидетельствовать, прежде всего, о том, что в условиях крайней нестабильности из-за вооруженного противостояния на данной территории возможности планировать будущее и реализовывать какие-либо цели ограничены, хотя, на наш взгляд, не исключено влияние индивидуальных особенностей личности.

Среди женщин второй группы наиболее распространенным является средний уровень мотивации $(41,4 \%)$, низкий уровень зафиксирован у 38,6 \% испытуемых женщин, 19,1\% респондентов имеют умеренно высокий уровень мотивации.

В ходе анализа полученных данных было установлено, что у респондентов-мужчин первой группы уровень мотивации на достижение успеха выше, чем у женщин этой группы (статистически значимые различия по $\varphi^{*}-$ критерию Фишера, при $p<0,05)$. Во второй группе проявилась такая же тенденция с небольшим снижением числа людей с высокой и средней мотивацией на успех. Однако, увеличилось количество мужчин с низким уровнем мотивации, что может свидетельствовать о влиянии на них экстремального образа жизни. Они указывают, что трудно стремиться к успеху в условиях интенсивных обстрелов и экономической нестабильности.

Мотивация на избегание неудач - это потребность человека в любой ситуации действовать так, чтобы результат был положительным. Поведенческая установка на избегание неудач приводит человека к необходимости минимизировать потери в ситуации достижения своих целей. Таких людей, как правило, отличает повышенная тревожность из-за постоянных сомнений и неуверенности в своих силах. В результате боязнь неудач приводит к частым эмоциональным спадам, занижению собственной значимости и самоэффективности, вследствие чего снижается качество жизни [8]. Мотив избегания неудач обычно связан со стремлением человека ставить перед собой слишком легкие задачи, возможность решения которых не вызывает сомнения. Задания могут быть также и слишком трудными, но их невыполнение не принесет разочарования, поскольку не рассматривается как неудача. Поэтому практическая деятельность индивида, стремящегося всеми способами избежать неудачи, чаще всего не соответствует его объективным возможностям и способностям.

Результаты изучения мотивации на избегание неудач в двух исследуемых группах представлены в табл. 2.

Таблица 2

Выраженность мотиващии на избегание неудач (опросник Т. Элерса) в двух исследуемых группах (в \%)

\begin{tabular}{|c|l|r|r|r|r|}
\hline \multicolumn{2}{|c|}{ Параметры } & HM3 & \multicolumn{1}{|c|}{ СУМ } & BУМ & ВУМИН \\
\hline \multirow{2}{*}{$\begin{array}{c}\text { Первая группа } \\
\text { (РМО) }\end{array}$} & мужчины $(n=134)$ & 29,1 & 60,4 & 10,5 & - \\
\cline { 2 - 6 } & женщины $(n=201)$ & $7,5 *$ & 59,7 & $28,3^{*}$ & 4,5 \\
\hline \multirow{2}{*}{$\begin{array}{c}\text { Вторая группа } \\
\text { (РИО) }\end{array}$} & мужчины $(n=168)$ & 25,1 & 52,8 & $22,1^{*}$ & - \\
\cline { 2 - 6 } & женщины $(n=220)$ & $2,7 *$ & 55,5 & $32,3 *$ & $9,5 *$ \\
\hline
\end{tabular}

Примечание: НМЗ - низкая мотивация к защите; СУМ - средний уровень мотивации; ВУМ высокий уровень мотивации; ВУМИН - слишком высокий уровень мотивации к избеганию неудач, защите. *статистически значимые различия при $\mathrm{p}<0,05$ (по $\varphi *-$ критерию Фишера).

В первой группе (PMO) у большинства мужчин $(60,4 \%)$ и женщин $(59,7 \%)$ превалирует средний уровень мотивации на избегание неудач. На практике такая поведенческая установка означает ярко выраженную зависимость действий индивида от ситуации, что в условиях вооруженного конфликта является наиболее приемлемым. Практически у трети мужчин $(29,1$ \%) обнаружена низкая мотива-

\section{Baikal Research Journal}


ция к защите, они в большей степени нацелены на успех и достижение целей. Высокий уровень мотивации на избегание неудач выявлен лишь у 10,5 \% исследуемых. В отличие от мужчин этой группы треть женщин $(28,3 \%)$ имеет высокий уровень мотивации на избегание неудач и небольшое количество $(7,5 \%)-$ низкий. Следовательно, мужчины первой группы более нацелены на успех, а женщины - на избегание неудач, о чем свидетельствуют и статистически значимые различия (по $\varphi^{*}-$ критерию Фишера, при $p<0,05$ ).

У большинства респондентов второй группы (52,8 \% мужчин и 55,5\% женщин) наиболее выражена средняя мотивация к защите, что характеризует их как людей, адекватно относящихся к достижению целей и выполнению, поставленных задач. Низкий уровень мотивации к защите выявлен у четверти мужчин $(25,1 \%)$ и незначительной части женщин $(2,7 \%)$, что ниже, чем в первой группе, но статистически значимые различия выявлены только в женской выборке (по $\varphi^{*}-$ критерию Фишера, при $\left.\mathrm{p}<0,05\right)$. Высокий уровень мотивации к защите характерен для 22,1 \% мужчин и 32,3 \% женщин, у $9,5 \%$ респондентов из числа женщин зафиксирован слишком высокий уровень мотивации. Подчеркнем, что доминирование у человека мотива избегания неудач может привести к сниженной самооценке, потере веры в себя. У таких людей, как правило, наблюдается низкий уровень развития мотивации достижения.

Таким образом, для мужчин исследуемых групп более свойственна мотивация на достижение успеха, а для женщин - ориентация на избегание неудач. У людей, проживающих в районах интенсивных обстрелов (вторая группа) наблюдается тенденция к снижению уровня мотивации на успех и увеличению уровня мотивации к защите, в большей степени у женщин.

Как известно, чем выше у человека самооценка, тем более он активен и нацелен на достижения. Потребность в достижении превращается в таком случае в личностное свойство и поведенческую установку. Изучение указанных характеристик среди наших респондентов проводилось при помощи шкалы оценки потребности в достижении Ю.М. Орлова. Результаты, полученные в ходе исследования потребностей в достижении, представлены на рис. 3.

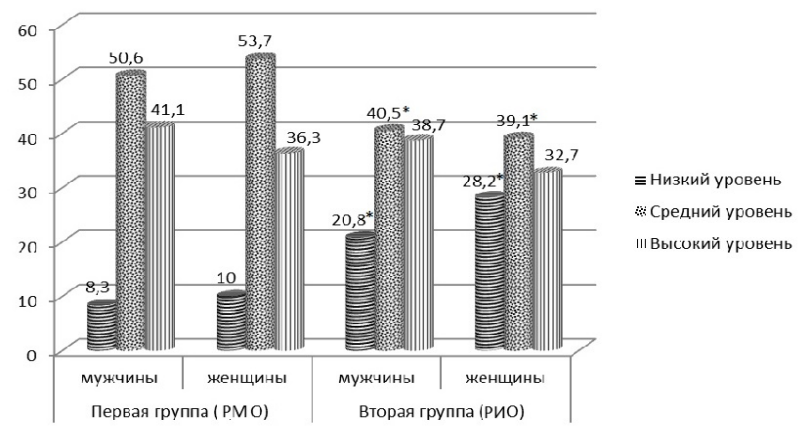

Примечания: *статистически значимые различия при $\mathrm{p}<0,05$ (по $\varphi^{*}-$ критерию Фишера)

Рис. 3. Выраженность потребностей в достижении иели у респондентов двух исследуельх групп (в \%)

Как видно на рис. 3 более половины мужчин (50,6 \%) и женщин $(53,7 \%)$ первой группы (PMO) имеют средний уровень потребностей в достижении целей, а также у значительной части респондентов этой группы $(41,1 \%$ мужчин и $36,3 \%$ женщин) выявлен высокий уровень данной потребности. Полученные результаты

\section{Baikal Research Journal}


говорят о том, что у большинства испытуемых данной группы присутствует потребность ставить цели и достигать их, несмотря на вооруженный конфликт на территории, где они проживают (малоинтенсивные районы обстрелов). У незначительного количества исследуемых первой группы (8,3 \% мужчин и $10 \%$ женщин) обнаружен низкий уровень потребностей в достижении целей, что может свидетельствовать, прежде всего, об особенностях их характера, а также индивидуальности переживания стрессовых ситуаций.

Результаты второй группы (РИО) имеют статистически значимые различия с результатами первой группы (РМО) по $\varphi^{*}-$ критерию Фишера, при $p<0,05$. Так, 20,8 \% мужчин и 28,2 \% женщин второй группы имеют низкий уровень потребности в достижении, что может характеризоваться соответствующим уровнем переживания успеха-неудачи в деятельности, неудовлетворенности достигнутым, настойчивости в достижении своих целей, уверенности в себе.

Средний уровень достижения целей у респондентов второй группы (РИО) в сравнении с первой группой имеет тенденцию к снижению: данный параметр характерен для 40,5 \% мужчин и 39,1 \% женщин (при р $<0,05$ по $\varphi^{*}-$ критерию Фишера). Высокий уровень потребности в достижении обнаружен у трети респондентов $(36,7 \%$ мужчин и 32,7 \% женщин), и хотя статистически значимых различий не выявлено, очевидна тенденция к снижению этого уровня в сравнении с первой группой.

Таким образом, у респондентов первой группы в основном отмечаются хорошо развитые потребности в достижении цели и их реализации, тогда как у участников исследования второй группы прослеживается выраженная тенденция к снижению значимости этой потребности.

Как указывает М. Аргайл, феномен удовлетворённости жизнью имеет когнитивную природу, поскольку наблюдается вовлеченность когнитивных компонентов во многие сферы, которые связаны с удовлетворенностью различными сторонами жизни. Удовлетворенность жизнью - когнитивная и рефлексивная оценка, суждение о том, насколько все было и остается благополучным [9].

Для изучения когнитивной оценки соответствия жизненных обстоятельств ожиданиям индивида нами использовалась методика-шкала Э. Динера «Удовлетворенность жизнью» (SWLS), результаты которой представлены на рис. 4.

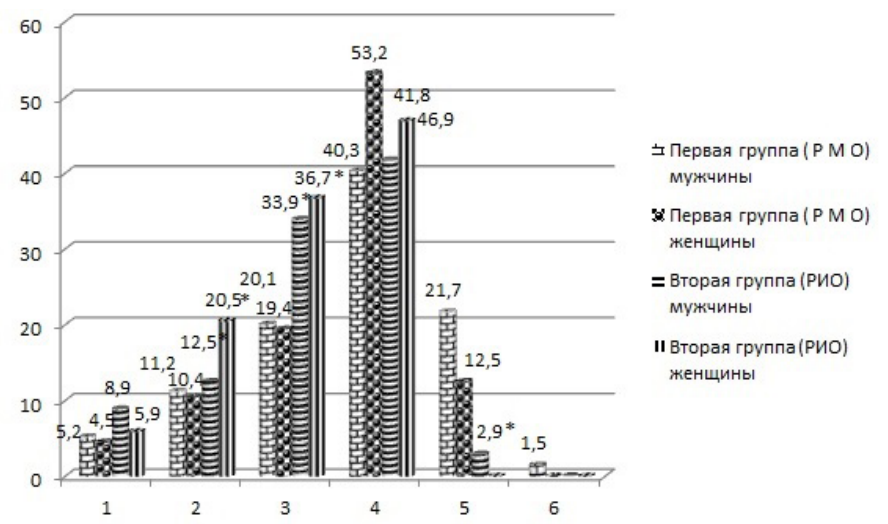

Примечание: 1. Выраженная неудовлетворенность. 2. Неудовлетворенность. 3. Немного ниже среднего уровня удовлетворенность. 4. Средняя удовлетворенность. 5. Удовлетворённость. 6. Чрезвычайная удовлетворенность.

* статистически значимые различия при $\mathrm{p}<0,05$ по $\varphi$ * - критерию Фишера

Рис. 4. Выраженность удовлетворенности жизни (Э. Динер, SWLS) в двyx гpynnax (в \%)

\section{Baikal Research Journal}


Анализируя полученные результаты можно отметить, что в первой группе выявлена в основном средняя удовлетворенность жизнью (40,3\% мужчин и $53,2 \%$ женщин), недовольных жизнью немного - около 20 \% исследуемых. Небольшое количество респондентов (16,4 \% мужчин и 14,9 \% женщин) выразили свою неудовлетворенность в разной степени. Полностью удовлетворены жизнью лишь $21,7 \%$ мужчин и $12,5 \%$ женщин (достоверно значимы различия при $p<0,05$ по $\varphi^{*}$ - критерию Фишера).

Во второй группе также значительную долю составляют респонденты, оценившие удовлетворенность жизнью как среднюю (41,8 \% мужчин и 46,9 \% женщин). Однако, оценка «немного ниже среднего уровня удовлетворенности» была выбрана большим количеством респондентов, чем в первой группе $(33,9$ \% мужчин и $36,7 \%$ женщин), что свидетельствует, возможно, о росте недовольства собственной жизнью под воздействием стрессогенной обстановки и интенсивных обстрелов территорий, где они проживают. Также среди женщин увеличился процент недовольных жизнью $(20,5 \%)$ в сравнении с первой группой $(10,4 \%)$. Лишь небольшое количество мужчин $(2,9 \%)$ удовлетворено жизнью, среди женщин таковых не выявлено. Результаты статистически значимо подтверждены при $p<0,05$ по $\varphi^{*}$ - критерию Фишера.

Как показывают результаты, полученные в ходе исследования степени удовлетворенности жизнью (по методике Э. Динера) у респондентов обеих исследуемых групп наиболее выраженным является параметр «средняя удовлетворенностью жизнью». Подобные результаты свидетельствуют о средней оценке респондентами собственной жизни. Выявлена также тенденция увеличения количества людей недовольных жизнью во второй группе, в сравнении с первой, что подтверждается достоверно значимыми различиями (при $p<0,05$ по $\varphi^{*}-$ критерию Фишера). У более трети респондентов второй группы $(33,9 \%$ мужчин и $36,7 \%$ женщин) преобладает оценка удовлетворенности жизнью «немного ниже среднего уровня», что может свидетельствовать о влиянии интенсивных обстрелов на качество их жизни.

Следует подчеркнуть, что полученные данные психологического исследования относительно оценки качества и удовлетворенности жизнью респондентов в условиях вооруженного конфликта подтверждаются также и результатами индивидуальных бесед, позволившими выяснить субъективное восприятие респондентами сложившейся реальности. Установлено, что люди, проживающие в районах интенсивных обстрелов, оценивают свою жизнь на среднем и заниженном уровне, а население из районов малоинтенсивных обстрелов считают ее более или менее нормальной (на среднем уровне). Безусловно, эта оценка зависит и от многих факторов, например, от личностных качеств индивида, степени его идентичности с новыми условиями жизнедеятельности. Как было установлено из бесед, лишь небольшая часть респондентов первой группы (12,2\% от их общего числа) и некоторое количество опрошенных второй группы $(21,3$ \%) хотят вернуться в свою прежнюю жизнь, которая их устраивала. Они не могут принять изменившиеся условия, сравнивают качество своей жизни до конфликта и после, что, естественно, влияет на их оценку удовлетворенности жизнью. Более половины интервьюированных первой группы $(58,8 \%)$ и $43 \%$ во второй группе считают свою жизнь удовлетворительной, надеются на лучшее, верят, что конфликт разрешится и качество их жизни улучшится.

Анализируя результаты изучения качества и удовлетворенности жизнью людей, проживающих в условиях вооруженного конфликта, нами были зафиксированы тесные корреляционные связи между показателями использованных методик (по Спирмену), которые представлены в табл. 3.

\section{Baikal Research Journal}


Таблица 3

Результаты корреляционного анализа между показателяли использованных методик (по Спирлену)

\begin{tabular}{|c|c|c|c|c|c|c|c|c|c|c|c|}
\hline & НКЖ & СКЖ & НиКЖ & УЖ & СУЖ & НСУЖ & НЖ & ВПДЦ & НМЗ & СУМЗ & ВУМЗ \\
\hline ВМУ &, $237 *$ & 0,128 &,$- 489 *$ &, $269 *$ &, $321 *$ & $-0,116$ &,$- 204 *$ &, $318 *$ &, $596 * *$ & 0,027 & $-0,199$ \\
\hline УВМУ &, $264 *$ &, $278 *$ & $-0,018$ &, $315 *$ &, $273 *$ & $-0,025$ & $-0,019$ &, $422 *$ &, $261 *$ & 0,034 & $-0,046$ \\
\hline СМУ & 0,104 &, $323 *$ & $-0,057$ & 0,124 &, $299 *$ & $-0,157$ & 0,021 & 0,135 & $-0,056$ &, $0274 *$ & $-0,023$ \\
\hline НМУ & $-0,048$ & 0,012 & 0,125 & 0,034 & 0,087 & 0,112 & 0,145 & $-0,126$ & $-0,187$ &, $245 *$ &, $589 *$ \\
\hline ВУМЗ & $-0,103$ & 0,048 & 0,198 & $-0,123$ & 0,078 & 0,076 &, $576 *$ & $-0,156$ & - & - & - \\
\hline СУМЗ & 0,069 & 0,108 & 0,125 & $-0,097$ & 0,123 & 0,126 & 0,045 & $-0,095$ & - & - & - \\
\hline НМЗ & 0,115 & $-0,132$ & $-0,193$ & 0,108 &, $268 *$ & $-0,124$ & $-0,131$ &, $279 *$ & - & - & - \\
\hline ВПДЦ &, $236 *$ & 0,021 &,$- 251 *$ &, $387 *$ & 0,045 & $-0,128$ &,$- 341 *$ & - & 0,187 & 0,023 &,$- 235 *$ \\
\hline СПДЦ & 0,123 &, $258 *$ & $-0,102$ & 0,135 &, $342 *$ & $-0,047$ & $-0,127$ & - & 0,146 & 0,136 & $-0,062$ \\
\hline НПДЦ & 0,023 & $-0,089$ &, $265 *$ & 0,015 & 0,006 & 0,145 & 0,187 & - & $-0,103$ & 0,007 &, $368 *$ \\
\hline УЖ &, $237 *$ & 0,131 &,$- 267 *$ & - & - & - & - &, $297 *$ & 0,125 & 0,094 & $-0,105$ \\
\hline СУЖ & 0,117 & 0,193 & 0,004 & - & - & - & - & 0,043 & 0,111 & 0,049 & 0,028 \\
\hline НЖ &,$- 228 *$ & $-0,179$ &, $365 *$ & - & - & - & - &,$- 342 *$ & $-0,076$ & $-0,052$ & 0,125 \\
\hline
\end{tabular}

Примечание:* Корреляция значима на уровне 0,$05 ; * *$ Корреляция значима на уровне 0,01 .

- методика З.Ф. Дудченко. НКЖ - нормальное качество жизни; СКЖ — среднее качество жизни; НиКЖ - низкое качество жизни;

- методика Т. Элерса. ВМУ - слишком высокий уровень мотивации к успеху; УВМУ - умеренно высокий уровень мотивации к успеху; СМУ - средний уровень мотивации к успеху; НМУ - низкая мотивация к успеху; ВУМЗ - высокий уровень мотивации к защите; СУМЗ - средний уровень мотивации к избеганию неудач; НМЗ - низкая мотивация к защите;

- методика Ю.М. Орлова. ВПДЦ - высокий уровень потребностей в достижении целей; СПДЦ - средний уровень потребностей в достижении целей; НПДЦ - низкий уровень потребностей в достижении целей;

- методика Э. Динера. УЖ - удовлетворённость жизнью; СУЖ - средняя удовлетворенность жизнью; НСУЖ - немного ниже среднего уровня удовлетворенность жизнью; НЖ - неудовлетворенность жизнью.

По результатам корреляционного анализа установлено, что качество жизни населения, проживающего в зоне вооруженного конфликта, удовлетворенность ею, зависят от уровней мотивации на достижение успеха и защиты, потребностей в достижении целей. Чем выше уровень мотивации на успех и достижение целей, ниже мотивация к защите, тем выше и удовлетворенность жизнью и оценка ее качества.

Таким образом, на основании вышеизложенного можно сделать выводы о том, что качество жизни населения, проживающего непосредственно в зоне вооруженного конфликта, оценивается им на среднем уровне и зависит от мотивации на успех и защиты, степени потребностей в достижении целей и удовлетворенности жизнью.

Перспективы проведенного исследования представляются нам в дальнейшем проведении анализе сущностных характеристик качества жизни респондентов не только в условиях конфликта, а и в период постконфликтного восстановления, в необходимости разработки коррекционных и реадаптационных мероприятий для

\section{Baikal Research Journal}


активизации адаптационного потенциала некоторых групп населения, что требует дополнительных исследований и выработки на их основе конкретных практических шагов.

\section{Список использованной литературы}

1. Future time perspective as a motivational variable: content and extension of future goals affect the quantity and quality of motivation / W. Lens [et al.] // Japanese psychological research. - 2012. - Vol. 54, № 3. - P. 321-333.

2. Рядинская Е. Н. Индивидуально-психологические состояния жителей, проживающих в условиях вооруженного конфликта, как предикторы их адаптационного потенциала / Е. Н. Рядинская // Вестник психофизиологии. - 2017. - № 3. - С. 65-71.

3. Lennings C. J. Optimism, satisfaction and time perspective in the elderly / C. J. Lennings // International journal of aging and human development. - 2000. — Vol. 51. P. 168-181.

4. Котельникова И. А. Развитие мотивации достижения успеха как фактор стрессоустойчивости личностикова / И. А. Котельникова // Концепт. - 2014. - Т. 30. — С. 16-20.

5. Maslow Abraham H. Towards a Psychology of Being / Abraham H. Maslow. - $3^{\text {rd }}$ ed. Hardcover : Wiley, 1998. - 320 p.

6. Абакумова И. В. Специфика индивидуально-психологических реакций личности, проживающей в зоне вооруженного конфликта / И. В. Абакумова, Е. Н. Рядинская // Научные ведомости Белгородского государственного университета. Серия: Гуманитарные науки. - 2017. - № 7 (256). - Вып. 33. - С. 177-181.

7. Kreitler S. Motivation and cognition: Forging an interdisciplinary perspective / S. Kreitler. - New York : Cambridge University Press, 2013. - 432 p. $332 \mathrm{c}$.

8. Аргайл М. Психология счастья / М. Аргайл. - 2-е изд. - СПб. : Питер, 2003. -

9. Нюттен Ж. Мотивация, действие и перспектива будущего / Ж. Нюттен. - М. : Смысл, 2004. - 608 с.

\section{References}

1. Lens W., Paixao M. P., Herrera D., Grobler A. Future time perspective as a motivational variable: content and extension of future goals affect the quantity and quality of motivation. Japanese psychological research, 2012, vol. 54, no. 3, pp. 321-333.

2. Ryadinskaya E. N. Individual psychological condition of residents living in an armed conflict environment, as predictors of their adaptive potential. Vestnik psikhofiziologii $=$ Psychophysiology news, 2017, no. 3, pp. 65-71. (In Russian).

3. Lennings C. J. Optimism, satisfaction and time perspective in the elderly. International journal of aging and human development, 2000, vol. 51, pp. 168-181.

4. Kotelnikova I. A. Development of success achievement motivation as a factor of individual stress resistance. Kontsept $=$ Koncept, 2014, vol. 30, pp. 16-20. (In Russian).

5. Maslow Abraham H. Towards a Psychology of Being. $3^{\text {rd }}$ ed. Hardcover, Wiley, 1998. 320 p.

6. Abakumova I. V., Ryadinskaya E. N. Specifics of individual psychological reactions of a person living in a zone of armed conflict. Nauchnye vedomosti Belgorodskogo gosudarstvennogo universiteta. Seriya: Gumanitarnye nauki = Belgorod State University Scientific Bulletin. Philology Journalism Pedagogy Psychology, 2017, no. 7 (256), iss. 33. pp. 177-181. (In Russian).

7. Kreitler S. Motivation and cognition: Forging an interdisciplinary perspective. New York, Cambridge University Press, 2013. 432 p.

8. Argyle M. The Psychology of Happiness. $2^{\text {nd }}$ ed. London, Routledge, 2001. 276 p. (Russ. ed.: Argyle M. Psikhologiya schast'ya. $2^{\text {nd }}$ ed. Saint Petersburg, Piter Publ., 2003. 332 p.).

9. Nuttin J. Motivation, Planning, and Action. London, Routledge, 1984. 251 p. (Russ. ed.: Nuttin J. Motivatsiya, deistvie i perspektiva budushchego. Moscow, Smysl Publ., 2004. 608 p.).

\section{Информация об авторе}

Рядинская Евгения Николаевна - кандидат психологических наук, доцент, докторант, Южный Федеральный университет, 44038, Россия, Ростов-на-Дону, ул. Нагибина, 13, e-mail: muchalola@mail.ru.

\section{Baikal Research Journal}




\section{Author}

Ryadinskaya Yevgenia Nikolayevna - PhD in Psychology, Associate Professor, Doctoral Student, Southern Federal University, 44038, 13 Nagibin St., Rostov-on-Don, e-mail: muchalola@mail.ru.

\section{Для цитирования}

Рядинская Е. Н. Анализ качества жизни мирного населения, проживающего в условиях вооруженного конфликта / Е.Н. Рядинская // Baikal Research Journal. — 2018. — T. 9, № 1. - DOI : 10.17150/2411-6262.2018.9(1).14.

\section{For Citation}

Ryadinskaya Ye. N. Analysis of Life Quality of Civilians Living in Armed Conflict Environment. Baikal Research Journal, 2018, vol. 9, no. 1. DOI: 10.17150/2411-6262.2018.9(1).14. (In Russian).

\section{Baikal Research Journal}

